\title{
DEL VIAJE FAMILIAR HASTA LOS GRANDOTES: MERCANCÍAS, COMUNIDAD Y FRONTERA EN LA PUNA ATACAMEÑA DEL SIGLO XX
}

\author{
FROM THE FAMILY JOURNEY UNTIL THE GRANDOTES: \\ GOODS, COMMUNITY AND BORDER AT THE PUNA ATACAMEÑA \\ DURING THE 2OTH CENTURY
}

\author{
Héctor Morales*, Alejandro Garcés**, Luis González,**, \\ Gisella Dibona $^{* * *}$, Juan Carlos Vilches ${ }^{* * *}$ y Rodrigo Azócar ${ }^{* * *}$
}

\begin{abstract}
Se ha escrito ampliamente acerca de los viajes realizados en la puna de Atacama, viajes provenientes desde ambos lados de la cordillera. En medio de parajes, se van entrelazando rutas por las que transitaron personas, animales y mercancías. En aquel ir y venir se fueron constituyendo distintas relaciones sociales que abarcaron territorios más extensos que la propia comunidadlocalidad. Tradicionalmente se ha entendido comunidad como la unidad socioorganizativa de los grupos humanos que habitan la puna de Atacama, en cierta medida como una clausura espacial de las relaciones sociales, perspectiva teórico-analítica que deja espacios sombríos que terminan por constituir un imaginario estable de estos grupos. Estas sombras han invisibilizado las formas en que se han ido construyendo las relaciones sociales en territorios que exceden lo local y que permite ir representando formas de familias y liderazgo o "grandotes", que constituyen parte del sustrato sociológico del modo de habitar el espacio puneño. Se describirán tres tipos de viajes que dan cuenta de las características organizacionales de los grupos indígenas atacameños y collas en la zona, ilustrándose la emergencia de nuevas formas de construcción sociopolítica expresadas en distintas formas de liderazgo.

Palabras claves: Intercambio, familias, liderazgo, comunidad, caciques.
\end{abstract}

It has been extensively written about the journeys made in the puna of Atacama, journeys from both sides of the Andes. In between rural places, routes through which people have moved are intertwined. Coming and going, social relations that covered more extensive territories than the community/locality itself have been constructed. Traditionally, the community has been understood as the socio-organizational unit of the human groups that inhabit the Puna de Atacama, to a certain extent as a spatial closure of social relations, a theoretical-analytical perspective that leaves shadowy spaces that end up constituting a stable imaginary of these groups. These shadows have made invisible the ways in which social relations have been built in territories that exceed the local, and that can be represented by forms of families and leadership or "big men", which are part of the sociological substratum of the inhabiting way in the Puna area. Three types of trips will be described as they give an impression of the organizational features of the atacama and colla indigenous groups in the area, illustrating the emergence of new forms of socio-political construction expressed in different forms of leadership.

Key words: Exchange, families, leadership, community, Caciques.

\section{Introducción}

El problema central que se discutirá en este artículo guarda relación con los viajes de intercambio realizados en la puna de Atacama durante el siglo XX. La entrada a este fenómeno propio del mundo andino se ha visto impregnado por enfoques ambientalistas sobre la verticalidad de los pisos ecológicos (Murra, 1975) y un sustancialismo asociado a la reciprocidad en estas comunidades (Alberti y Mayer, 1977) producto de una baja diferenciación social.

Los resultados de esta investigación nos permiten presentar datos que apuntarían a una sociedad altamente diferenciada, con la existencia de jerarquías sociales como un arriero-jefe a modo de cacique que coordinaba y ejecutaba el traslado de mercancías y animales por la puna atacameña;

\footnotetext{
* Universidad de Chile. Departamento de Antropología, Laboratorio de Etnografía. Santiago, Chile. Correo electrónico: hmorales@uchile.cl

** Universidad Católica del Norte. Instituto de Arqueología y Antropología. San Pedro de Atacama, Chile. Correo electrónico: ajgarces@gmail.com

*** Universidad de Chile. Laboratorio de Etnografía. Santiago, Chile. Correos electrónicos: 1.gonz.cortes@ gmail.com; gisella. dibona@gmail.com; jcvilches@ug.uchile.cl; rodrigo.azocar.d@gmail.com
} 
celebrando tratos o contratos con empresarios de alimentos-carnes, pagando salarios a unos trabajadores y con especies a otros. Se mostrará tres casos de movilidad asociada a viajes familiares, de comercio y de contrabando. Se busca caracterizar los viajes por su singularidad social, comercial, económica y geográfica derivada del tráfico permanente de productos diversos, bajo modalidades de trabajos diferenciados y estratificados. Los registros que exponemos han sido producidos a partir de trabajos de campo etnográficos realizados entre el 2016 y 2107 dentro del proyecto Fondecyt $\mathrm{N}^{\mathrm{o}} 1160963$ y Núcleo Milenio MOVYT, Iniciativa Milenio, Ministerio de Economía.

Desde hace un tiempo se replantean las investigaciones concernientes a los viajes de intercambios y los restos materiales que fueron diseminados a su paso. Se vuelven entonces centrales aquellos espacios producidos por el tránsito de personas, que muchas veces han sido descritos como inhabitados por su baja presencia de cultura material y aparente hostilidad geográfica. Un concepto clave utilizado es el de "nodos", el que permite dar cuenta de los espacios presentes entre los distintos puntos de la puna. Actualmente la "arqueología internodal contribuye a la investigación de los procesos sociales a través del estudio de las áreas entre nodos, es decir, aquellos lugares donde las actividades humanas y las interacciones tienden a agruparse" (Berenguer y Pimentel, 2017:5). Es decir, logran hacer complejo el espacio que antaño se veía desprovisto de ocupación humana o con un bajo nivel de incidencia, pues serían los lugares donde ocurrirían aspectos centrales de los intercambios. Otro concepto relevante para esta investigación es el de "cacique". Durante el siglo XVIII, cuando la Corona española aún tenía presencia política-administrativa en la puna, ello se ponía de manifiesto en el cobro de tributos indígenas. El indio tributario es aquel que tributa un monto con lo que se le otorgan derechos en su comunidad de origen, pago que era recaudado por un "cacique", un mediador indígena. La interrogante que surge es ¿qué sustentaba la continuidad en el pago de tributos de un tipo de categoría pudiendo pagar en la condición de indio forastero? Algunos autores plantean que existía una cierta conveniencia en mantener los privilegios en la comunidad de origen ${ }^{1}$. A veces solo el indio tributario se movilizaba, mientras que su familia se quedaba. Se establecían alianzas matrimoniales y de compadrazgo que al mismo tiempo dotaban a los grupos de un carácter interétnico, a diferencia del modelo complementario de los Andes Centrales, en donde se lograría la autonomía de cada grupo étnico (Hidalgo y Manríquez, 2004; Haber y Lema, 2006).

Esta investigación levanta tipología de viajes que permite en términos políticos o etnopolíticos observar una cierta reemergencia o continuidad de la figura del cacique, ahora trasmutado en grandote. En este sentido, daremos cuenta de cómo fenómenos que han sido analizados bajo patrones rígidos pueden manifestarse con una flexibilidad mayor y propia de cada lugar. En esta línea el legado de Murra (1975) introduce una escala macrorregional dejando sombras y omitiendo un ejercicio reflexivo de ciertos aspectos fundamentales asociados a las dinámicas microlocales, pues la sumatoria de las singularidades sociales podrían no coincidir con las grandes dinámicas regionales asociadas a la verticalidad y reciprocidad enunciada para los Andes (Garcés y Maureira, 2018).

\section{Viajes y movimientos}

La arriería suele definirse como el transporte de mercadería y traslado de animales en pie para su venta. Esta actividad constituía un oficio no solo especializado sino también jerarquizado. La conducción de mulas cargadas podía realizarse por senderos con pocas pasturas y aguadas, por lo que generalmente atravesaban todos los "despoblados" por donde se accedía más rápidamente a los centros mineros del Alto Bolivia y Perú (García et al., 2002; Quesada et al., 2007; Conti y Sica, 2011).

Durante todo el siglo XX la arriería desde Salta hacia las costas chilenas fue una actividad relevante y especializada, que involucraba a diferentes sectores sociales, desde las elites mercantiles hasta los sectores indígenas pastoriles de la puna. Esta actividad revestía la característica de una labor desarrollada a nivel regional tendiente a generar excedentes monetarios y su ulterior acumulación por los distintos segmentos comprometidos. Molina (2011) describe los viajes en la época de la consolidación de la República y parte del siglo XX. Él distingue dos tipos de arriería en la puna atacameña: una "hacendal", que tenía como eje central el abastecimiento de carne hacia los polos mineros productivos y, "otro", correspondiente al tráfico caravanero familiar de intercambio local. La premisa se centra en que los viajes de intercambio 
local se realizaban basados en relaciones sociales que evitaban los controles policiales. Sin embargo, es importante preguntarse ¿cómo se podrían evitar controles policiales cuando la presencia estatal era relativamente baja?, es decir ¿efectivamente se evitaban los controles, o simplemente no existía tal control? Al menos hasta fines del siglo XX no estaba del todo presente el Estado en la puna de Atacama. Se retomará este punto cuando se desarrolle la dinámica de los viajes, pero al menos permite visibilizar la estabilidad de relaciones sociales estructurantes de los intercambios. La existencia y creación de lazos de amistad, compadrazgo y parentesco entre estas localidades favorecieron el intercambio transfronterizo (Molina, 2011; Londoño, 2018).

Por otra parte, el traslado de productos del siglo XX se encuentra descrito en numerosos trabajos (Bowman, 1924; Latcham, 1938; Mostny, 1954). Bajo distintas perspectivas se ha escrito respecto de los viajes realizados por los habitantes de dichos parajes: Benedetti (2005), Benedetti y Argañaraz (2001), Sanhueza (2001) y Londoño (2018). Su principal aproximación ha sido por la problemática de la construcción de los Estados nacionales y cómo estos han impactado los intercambios. "A lo largo del siglo XIX se suceden una serie de textos que expresan los deseos modernizadores de expansión capitalista, y ven a la Puna de Atacama al servicio de esos deseos" (Haber y Lema, 2006:6). Otros autores mencionan el intercambio, pero centrado en una práctica realizada desde un pueblo, como es el caso de Toconao (Núñez, 2002), presentándose como una práctica ancestral de la que en la actualidad no quedaría nada.

Si entendemos la frontera como la línea que divide países, expresa normatividad y regula el tránsito en un territorio en particular, podríamos decir que esta se encuentra en cierta medida ausente en la puna durante gran parte del siglo XX. Es a partir de la seguridad fronteriza de las décadas 70 y 80 en Bolivia, Argentina y Chile (coincidente con las dictaduras militares en dichos países), y luego en los 90 con los procesos de apertura económico-comercial en la región, cuando se logra consolidar la frontera chileno-argentina, representándose quizá paradigmáticamente por la instalación del paso fronterizo y aduanero de Jama en 1991, que desplazó el funcionamiento del paso Huaytiquina-Talabre (Benedetti y Argañaraz, 2001), el paso Sico y el de Socompa. Esta historia de demarcaciones y fronteras se inicia después de la Guerra del Pacífico, periodo en donde países latinoamericanos entran en disputa por la demarcación de las fronteras.

Desde ese momento se puede plantear la diferenciación entre puna oriental y occidental en términos geopolíticos. Esto marcará un hito en la vida de las personas que habitan ese espacio, pues de un momento a otro se instalan líneas imaginarias que les impiden el tránsito que de antaño podían efectuar sin mayores preocupaciones. Un hecho relevante y presente en la memoria colectiva es la quema de burros procedentes de Argentina, que fue realizada allá por los años 90 en territorio chileno. En relación con estos hechos un exarriero de la localidad de Huáncar (Argentina) narra respecto de la detención del arriero Eloy²;
"si pue parece que una gente ha tenido problemas en Chile, los detuvieron. Fue el 94... estuvieron presos en Antofagasta... antes había sido detenido, le han quemado los animales... Ah, los quemaron... después han ido un diputado de Jujuy... con otros familiares y el cónsul y si como después de seis meses los han soltado" (exarriero Huáncar, 2017).

Frente a ese acontecimiento es que se ve reflejada la fuerza que toma la demarcación de las fronteras y sus controles aduaneros, y que si bien existían formalmente desde principios del siglo XX, no es sino hasta fines de los $80 \mathrm{y}$ principios de los 90 que toman relevancia para la vida de las personas. En este sentido, la puna es un espacio preexistente que rebasa las fronteras nacionales mediante nodos y conexiones entre distintos caminos y circuitos. Un agricultor de Socaire menciona que "era preferible hacer trueque en Argentina que ir a Calama".

La línea que aparece en la Figura 1 representa la división geopolítica de la puna. En términos concretos, esto se expresa en una división administrativa, por medio de ella se norma el territorio y tránsito entre Chile y Argentina. En lo específico, la línea divisoria con todo el aparataje que ello implica (control fronterizo policial, aduanas, entre otras) logra mermar los viajes. A continuación, y a base de la información obtenida por nuestra investigación, podemos distinguir tres tipos de viajes transfronterizos en el espacio de la puna atacameña. 


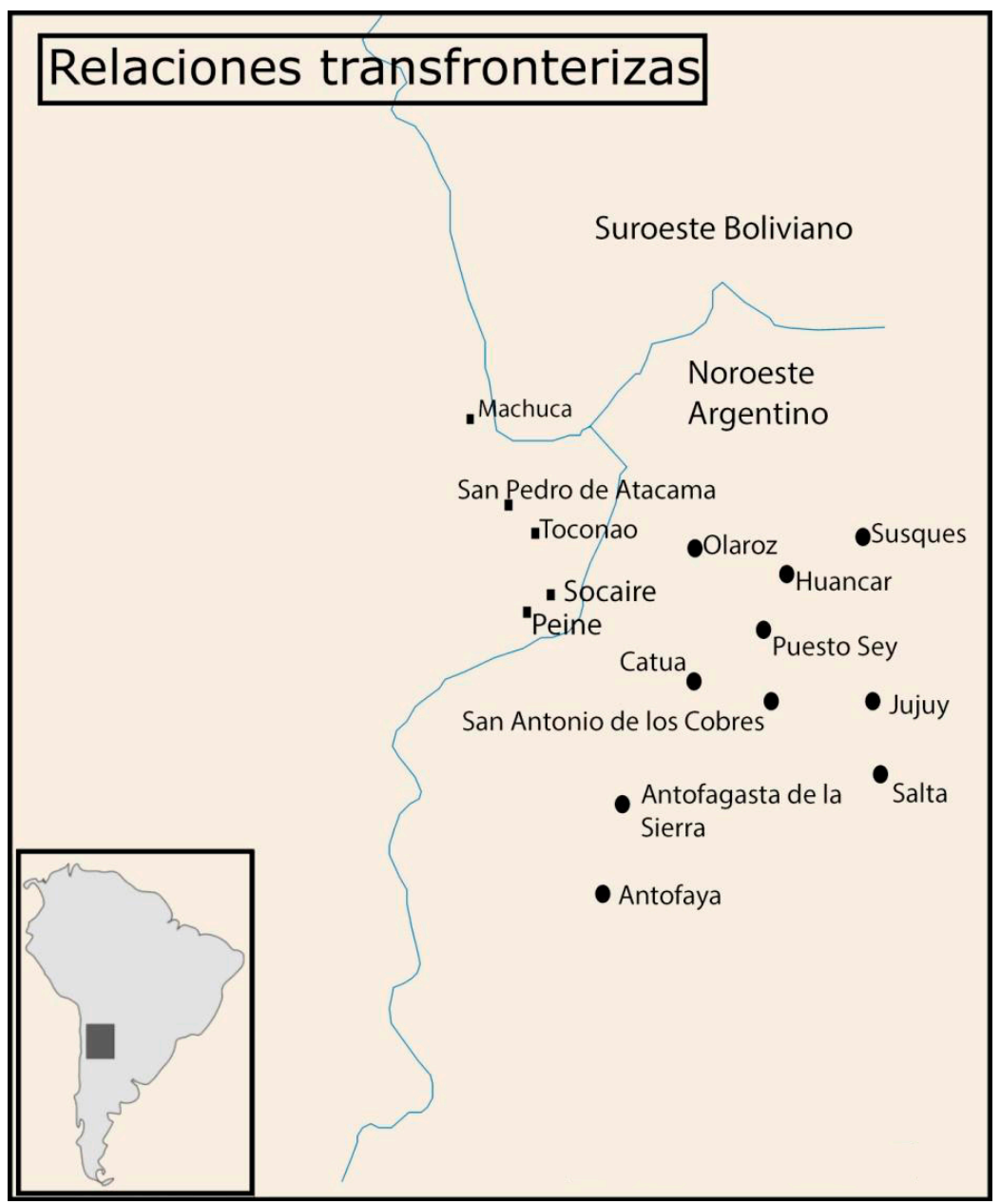

Figura 1. Frontera y pueblos de la puna atacameña. Fuente: Elaboración Luis González Cortés.

\section{A. "Viajes familiares tradicionales"}

Los viajes que se considerarán tradicionales son aquellos que tienen como objetivo el intercambio de productos agrícolas, pastoriles y agroindustriales. Los casos que se caracterizarán son los viajes que se realizaban entre Toconao y poblados cercanos a Susques (Toro, Coranzuli, Huancar), y los que se realizaban entre Talabre y Catua, principalmente. Para estos viajes es importante la perspectiva de la internodalidad (Berenguer y Pimentel, 2017), pues nos permite dar cuenta de las áreas comprometidas en el transecto desarrollado por las familias en estos viajes. Para contextualizar, Toconao era un reconocido espacio de actividad agrícola, donde la cosecha de frutos locales era sometida a un proceso de secado, generando grandes volúmenes de productos que eran demandados por viajeros provenientes de Argentina y otros poblados cercanos, los que no tenían un acceso constante o cercano a frutas. Comentan los habitantes del poblado de Toconao que había algunas familias que contaban con una gran cantidad de hectáreas para este tipo de cultivo. También había algunas casas que recibían a los viajeros que venían a intercambiar sus productos, con redes hechas por compadrazgo y algunos casos familiares: "En una casa donde tengan algún familiar o algún conocido. Ahí llegaban a la casa, no llegaban al pueblo en general o la comunidad, no" (exarriero, Toconao, 2017).

Cuando estos llegaban se disponían los productos que traían para ser intercambiados kilo a kilo en un trueque tradicional. Los viajeros argentinos traían productos derivados del extensivo pastoreo 
que se realizaba en su territorio y productos manufacturados de la creciente industria trasandina. Sin embargo, la productividad de Toconao atraía a algunos habitantes de poblados pastoriles, como es el caso de Talabre, cuyos habitantes intercambiaban sus productos pastoriles por frutos secos, los que a su vez eran llevados a Argentina, específicamente a Catua, para el trueque. Esta transacción resultaba provechosa para la obtención de alimentos no perecibles, industriales y queso.

Para los intercambios de Chile hacia Argentina los circuitos estaban direccionados en muchos casos por redes familiares constituidas en los pueblos, es decir, donde por la persistencia de esta actividad se fueron generando redes más afiatadas de socialización. Respecto de los viajes realizados desde los poblados de Toconao y Talabre se puede evidenciar su directa relación con los espacios de pastoreo que utilizan los comuneros durante las veranadas. Por ejemplo, en el caso de Talabre, las familias que pastorean durante el verano en la quebrada Ekar tienen un circuito desde ese punto hacia Argentina, mientras que otras que pastorean en la laguna Lejía continúan desde ese punto hacia la frontera. Lo mismo ocurre en Toconao.
Los comuneros también remiten a que era una práctica de subsistencia, donde los productos recaudados eran básicos para la economía familiar: "Porque nosotros el único sustento que teníamos era acá Toconao, y mis abuelitos que se iban a Argentina, a los trueques" (pastora, 2017, Toconao). Esta subsistencia era comprendida por las autoridades político-administrativas de la época, quienes al parecer no veían una mayor amenaza, hasta el endurecimiento de la frontera a fines de los años 80 y principio de los años 90 . Como se mencionó anteriormente, el episodio de la quema de llamas fue un hito importante para que esta actividad entrase en retroceso.

De este modo, llamamos viajes tradicionales aquellos que responden a una actividad familiar y donde cada uno de los miembros del conjunto cumplía una función específica. Las redes de trueque en estos viajes se establecieron desde remotos tiempos hasta el presente, siempre ligadas a un vínculo amistoso entre ambos lados de la frontera, según se asevera desde Talabre. "Se conserva tanto el trueque, así como también se conserva la amistad" (pastora, Talabre, 2017), donde se aprovechan las instancias de visita para intercambiar productos.

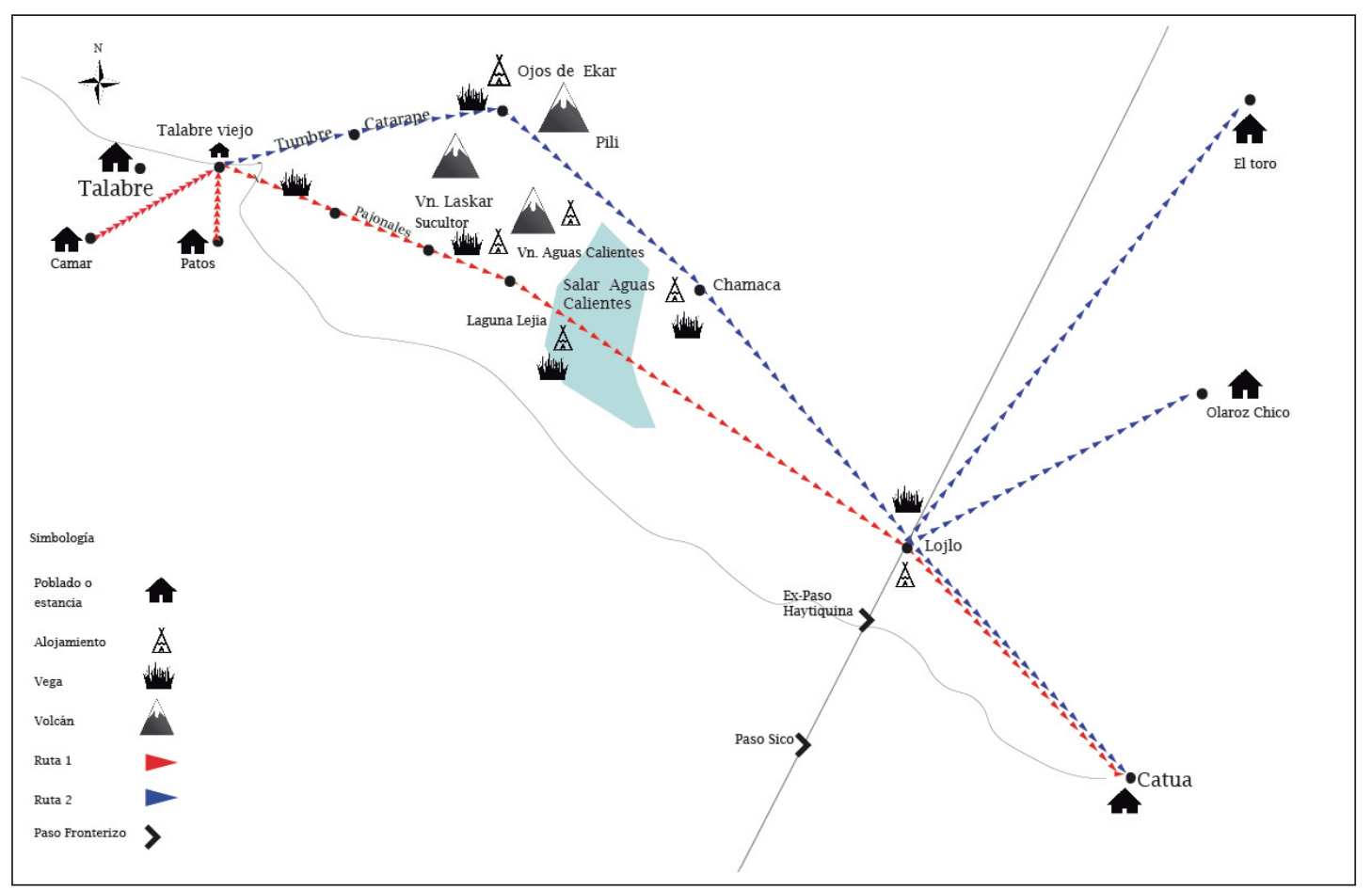

Figura 2. Espacialidad y conexiones Talabre-Catua.

Fuente: Elaboración Gisella Dibona. 
Incluso actualmente el intercambio se mantiene, pero ya no mediante el trueque sino que usando dinero en las transacciones de productos: "Vienen los sobrinos, siempre vienen para acá, a veces van a Camar que también tienen familia, San Pedro. Más viajan a San Pedro a comerciar, ahora con plata, ya no es como antes, traen mercadería" (pastor, Talabre, 2017).

Los vínculos de trueque de antaño dieron paso a redes familiares o viceversa, pues algunos viajeros fueron dejando familia a su paso y se fueron estableciendo a uno u otro lado de la cordillera forjando redes de parentesco en los pueblos atacameños chilenos y argentinos, o bien el contar con familiares en un lado propiciaba las condiciones de aventurar el intercambio de productos. Lo cierto es que los lazos familiares llevan a que se visiten unos a otros, aprovechando siempre de intercambiar productos (Morales et al., 2018).

Pero el intercambio no es la única vía de parentesco, pues las migraciones internacionales de familias que desde Chile se fueron a Argentina (o en sentido contrario), terminaron por establecer redes familiares a uno y otro lado de la cordillera, incluso yendo y viniendo entre uno y otro lado de la frontera a lo largo de sus vidas.

Se dice en Catua:

"Parece que llegó mi abuelo de allá de Chile. Se ha venido con la familia a la hacienda aquí... Aquí se quedaron, y ahí mi abuelo otra vez se ha ido a Talabre... Vino acá de peona y se fue con hijos... ella tuvo tres hijos acá, y de Chile ha traído dos, eran 5 ... algunos se han quedado acá y otros en Talabre" (comunero, Catua, 2016).
Y en Talabre:

"Es que aquí ya no se podía vivir, la gente era muy pobre, no se podía vivir, en Catua ya sí, había más pastoreo. Andando por allá, se juntaron, se casaron ahí y listo... En la escuela trabajé primero, después trabajé en la cantera que hay, la marmolera, ahí estuve trabajando y ahí cuando estaba trabajando iban con tropas para allá a buscar la mercadería y yo la cargaba allá" (pastor, Talabre, 2017).

Los talabreños no solo tenían y tienen familiares en Catua, sino también suelen tenerlos en Jama, Huáncar y Puesto Sey, siempre en Angentina, provincia de Jujuy. Por su parte los catueños, no solo tienen familiares en Talabre, sino también en Camar y San Pedro de Atacama, como vimos anteriormente. Con todo, lo importante en este tipo de viajes es la práctica del trueque funcional a economías domésticas de subsistencia, donde familias tanto de Chile como de Argentina intercambiaban productos que ellos generaban.

\section{B. Viajes de comercio}

Corresponde a los viajes en solitario o con algún socio, los que si bien presentan similitud con el primer caso, el conocimiento del espacio y los tipos de redes que utilizan les va diferenciando. Para ello tomaremos el caso de un comunero de Susques (Argentina), quien cuenta su manera de viajar por la puna.

Un exarriero de Susques cuenta que los meses de marzo solía viajar solo hacia la localidad de

Tabla 1. Productos que se intercambiaban en viajes familiares tradicionales.

\begin{tabular}{lccc}
\hline \multicolumn{1}{c}{ Productos } & Tipo & Origen & Destino \\
\hline $\begin{array}{l}\text { Trigo, maíz, chañar, algarrobo, maíz de } \\
\text { cape, orejón, membrillo charqueado, } \\
\text { haba, ajo, cebolla, lechuga }\end{array}$ & Agrícola & $\begin{array}{c}\text { Chile } \\
\text { Toconao, Talabre }\end{array}$ & Argentina \\
$\begin{array}{l}\text { Carne, queso de cabra, burros, ovejas, } \\
\text { lana de llama }\end{array}$ & $\begin{array}{l}\text { Ganadero } \\
\text { /derivados }\end{array}$ & Argentina & Toconao, Socaire, Talabre, \\
Mercadería, harina, frangolla & Industrial & $\begin{array}{c}\text { Sedro } \\
\text { Chintina }\end{array}$ \\
\hline
\end{tabular}

Fuente: Elaboración propia. 
Toconao, y así como él, muchos otros comuneros argentinos. Según su relato, el conocimiento que tiene del espacio se debía a las redes de amistad con otros viajeros que entregaban información acerca de lugares de descanso en las rutas troperas, siendo espacios de encuentro para ellos, como lo es la roca Ana y Pabla, el salar de Pujsa y Potor. El propósito de todos ellos era el intercambio por medio del trueque en la comunidad de Toconao, en tanto lugar donde se podía conseguir fruta más cerca que Jujuy en el espacio argentino.

"La verdad, la verdad, ya no había compañía ya, porque antes que uuuu. En el 80 aquí todos iban a burro. Todos iban así, nos encontrábamos, íbamos solitario. Pero ya los hijos no me quieren acompañar... entonces vamos con mi compañero... (en viaje a Toconao)... y nos hemos puesto a dormir y al otro día ya váyanse por ahí por donde han venido y sigan su camino y ya estábamos saliendo..." (exarriero, Susques, 2017).

Menciona que en los 90 disminuyeron los viajes a Chile, “... porque ya no se cambian todas las cosas, porque ya no tenía compañía, venía solo...”. Aquí se narra un episodio de ser detenido por Carabineros de frontera en Toconao;

"traiga pasas aquí y nos tomaron en retén y las dejan las pasas ahí, si no pasa nada ... la gente de Toconao se ha venido enterito todo el pueblo hermano, todo el pueblo se ha venido a favor de nosotros... También; dice Exaltación "Porque estaban controlando ehh $\mathrm{y}$ he ido a Jama porque estaban realizando control. Entonces yo me largué derecho y ya estuve aquí y no me pasó nada... pero estaban controlando ehh, y entonces me quieren acusar por acarrear... y me llaman... los pacos... ¡A Ahí en el retén!... Claro. ¡¡un golpe de Estado!! iiiQue mierda!!!”... llego ya como relaciones exteriores, como relaciones internacionales... De ahí la gente ya no fue con tanta frecuencia... Claro y entonces han dicho los pacos han dicho sabe que... los hombrecitos vienen noche y día caminando no han dormido... No valía la pena... entonces fue por la aduana entonces... cuando se pone la aduana... Fue por su Jama... Y porque me decía que ya el año 90 ya no fueron más, por algo me dijo... Porque, porque ya no se cambian todas las cosas, porque ya no tenía compañía, venía solo..."(exarriero, Susques, 2016).

Cuenta que cuando llegaba a Toconao era recibido por amistades, así también cuenta de su experiencia de viaje durante la dictadura, donde es apresado por contrabando y la comunidad de Toconao logra negociar con Carabineros su liberación. Esta modalidad de traslado de mercancía obedecía a un negocio donde las condiciones de trueque permitían aumentar la rentabilidad de las utilidades, por tanto los contactos, almacenes y distribución eran cuestiones claves. Estos comerciantes abastecían a localidades completas con productos de uno u otro lado de la frontera.

En marzo se intercambia una cantidad considerable de productos, en promedio a Toconao llegaban tres (3) remesas por día y cada remesa transportaba un promedio de 15 burros con 50 kilos cada uno, es decir, cada arriero lograba transportar 750 kilos y como cada día llegaban tres (3), significaba que a Toconao llegaban diariamente cerca de 2.250 kilos. En 30 días se trata de 67.500 kilos, es decir, 67,5 toneladas solo de ida y de vuelta 67,5 toneladas más, dando un total de 135 toneladas en esta ruta. Dependiendo del clima se ampliaba el periodo a febrero o parte de abril.

Sin duda 135 toneladas impone una dinámica económica voluminosa y requiere de una infraestructura necesaria para su almacenamiento, pesaje y posterior distribución. Es importante mencionar que la hoja de coca y alcohol eran mercancías que tenían un tratamiento especial debido a su carácter ilícito. Esta se dejaba en "trojas" a las afuera de las localidades para posteriormente ser trasladada a lugares con más resguardo. Esto hace suponer que el precio de esta mercancía era absolutamente superior a los abarrotes o frutos secos, pero era parte de la totalidad de productos transportados.

En Antofagasta de la Sierra nos menciona un comunero de 70 años que en una oportunidad "todo el pueblo quedó sin hoja de coca, la gente no quería trabajar, se cansaban y muchos andaban con tiritones, después de un mes de desabastecimiento, nos reunimos y un grupo de baqueanos del pueblo se fueron a comprar hoja de coca, primero se fueron a Chile y de ahí a Bolivia y de vuelta retornaron de 
Tabla 2. Productos que se intercambiaban en viajes de comercio.

\begin{tabular}{|c|c|c|c|c|c|}
\hline Productos & Tipo & Origen & Destino & Cantidades & Valores \\
\hline $\begin{array}{c}\text { Trigo, maíz, } \\
\text { chañar, algarrobo, } \\
\text { maíz de cape, } \\
\text { orejón, membrillo } \\
\text { charqueado, haba, } \\
\text { ajo, cebolla, lechuga }\end{array}$ & Agrícola & $\begin{array}{l}\text { Chile; } \\
\text { Toconao }\end{array}$ & Argentina & $\begin{array}{c}15 \text { a } 20 \text { burros, } \\
\text { cada uno se } \\
\text { cargaba con } 50 \\
\text { kilos }\end{array}$ & $\begin{array}{l}\text { "Cada kilo a kilo, un kilo de } \\
\text { pasas, un kilo de frangollo, un } \\
\text { kilo de orejón, un kilo de chañar, } \\
\text { bueno, y después el resto, carne } \\
\text { digamos, lo cambiábamos con } \\
\text { frutas frescas, con manzanas, con } \\
\text { peras, con duraznos, unas cuantas } \\
\text { uvas, y toda la fruta para traer, } \\
\text { pero lo que más valía. El queso y } \\
\text { nosotros lo que más llevábamos } \\
\text { era queso" (Hipólito Guzmán, } \\
\text { Susques) }\end{array}$ \\
\hline $\begin{array}{c}\text { Ollas, crema } \\
\text { lechuga, almidón de } \\
\text { mandioca, máquina } \\
\text { de coser }\end{array}$ & Manufacturado & $\begin{array}{l}\text { Chile; } \\
\text { San Pedro, } \\
\text { Calama }\end{array}$ & Argentina & $\begin{array}{c}15 \text { a } 20 \text { burros, } \\
\text { cada uno se } \\
\text { cargaba con } 50 \\
\text { kilos }\end{array}$ & 16 llamas por máquina de coser \\
\hline $\begin{array}{c}\text { Carne, queso de } \\
\text { cabra, burros, ovejas, } \\
\text { lana de llama }\end{array}$ & Ganadero & Argentina & $\begin{array}{c}\text { Chile; } \\
\text { Toconao, } \\
\text { Socaire, } \\
\text { Talabre, San } \\
\text { Pedro }\end{array}$ & 100,150 burros & \\
\hline $\begin{array}{l}\text { Mercadería, harina, } \\
\text { frangolla }\end{array}$ & Manufacturado & $\begin{array}{l}\text { Argentina; } \\
\text { Valles de } \\
\text { Salta y Jujuy }\end{array}$ & $\begin{array}{l}\text { Toconao, } \\
\text { Socaire, } \\
\text { Talabre. }\end{array}$ & $\begin{array}{l}15 \text { a } 20 \text { burros } \\
\text { cada uno se } \\
\text { cargaba con } 50 \\
\text { kilos }\end{array}$ & \\
\hline
\end{tabular}

Fuente: Elaboración propia.

la misma manera, es jodido lo de la hoja, es muy necesaria por el trabajo, el calor, el frío, el viento, ayuda mucho en el trabajo" (comunero, Antofagasta de la Sierra, 2017).

Este fragmento nos muestra la importancia y el valor de la hoja de coca en el trabajo puneño. Con toda probabilidad el alcohol tiene características muy similares. Otro producto que también gozaba de importancia eran los sacos de lana, pues con ella se activaban varios hechos relevantes para el modo de vida puneño: trasquilar llamos u ovejas, luego ovillar, meter en sacos, tejer ropa y abrigos para la vestimenta, y la producción de telares, tintes, hondas y sogas. Esto cerraba un círculo virtuoso de producción y reproducción de la vida en la puna.

\section{Movimiento de mercancías y contrabando. Los grandotes}

Esta actividad revestía la característica de una labor desarrollada a nivel regional tendiente a generar excedentes monetarios y su ulterior acumulación por los distintos segmentos comprometidos.
Nos centraremos en los intermediarios puneños o arrieros-jefes, caciques locales que transportaban toros a modo de flete, previo acuerdo con los grandes abastecedores de carne como Andrónico Abaroa Rivas, que desde 1916 encarga el traslado de ganado vivo por las serranías puneñas y que más tarde (1948) su hijo Juan Abaroa lo haría de igual manera hasta la década de 1960, agregando paralelamente el traslado vía ferroviaria por el paso Socompa. Esto nos revela un contexto de contactos, tratos y coordinaciones que harán posible este negocio de una de las más grandes familias acaudaladas de este país. Las Figuras 3 y 4 muestran la espacialidades y conexiones aquí comprendidas.

Como se mencionó, la arriería se asocia al transporte de mercadería y traslado de animales en pie para su venta, donde el traslado podía realizarse por caminos con pocas pasturas y aguadas, por lo que generalmente atravesaban por lugares inhabitados, pero directo a los destinos de entrega de animales o mercancías. Para el caso tratado aquí, ocurre lo contrario. La conducción de toros necesitaba tierras más fértiles, razón por la que utilizaban los caminos 


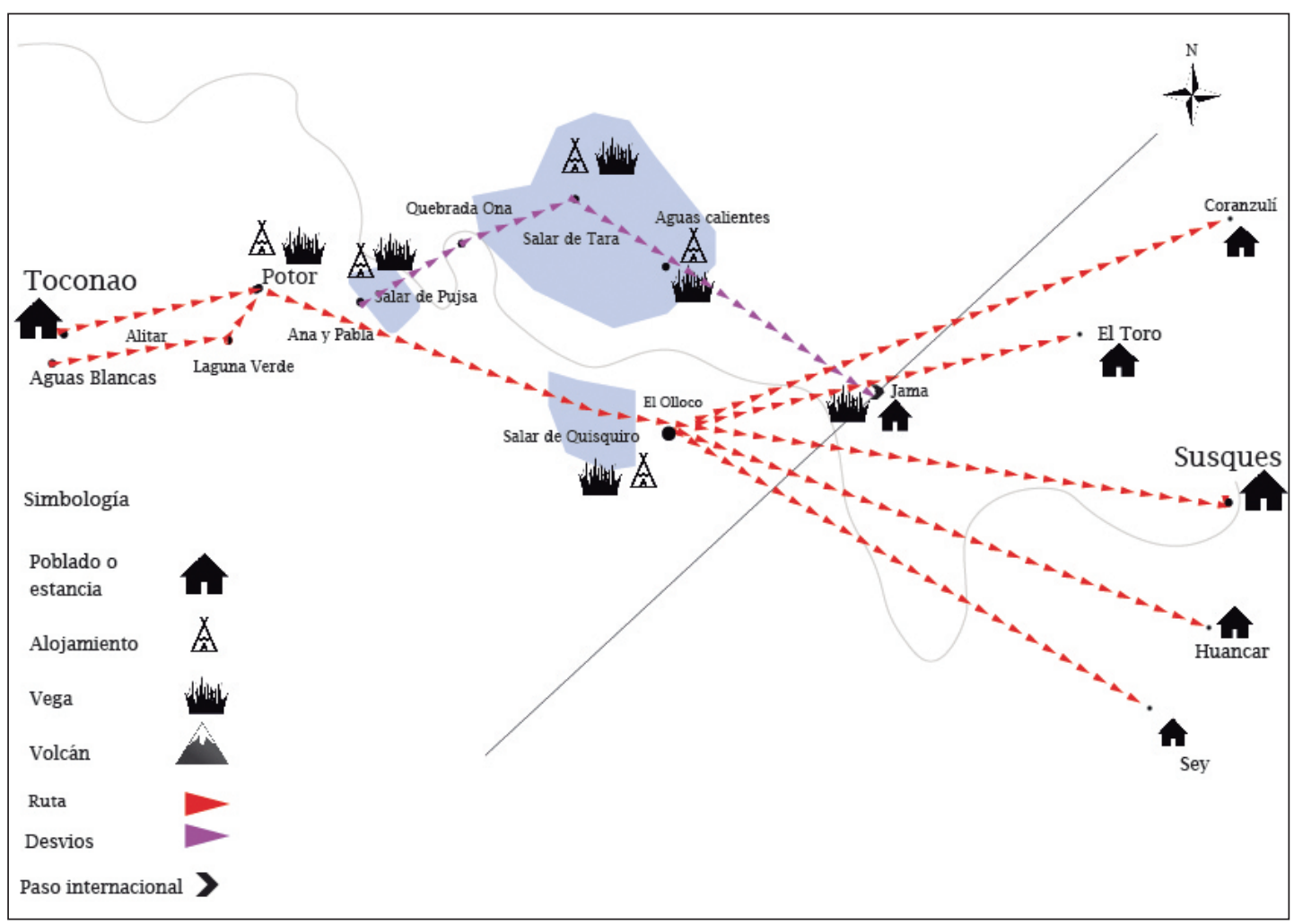

Figura 3. Espacialidad y conexiones Toconao-Susques.

Fuente: Elaboración Gisella Dibona.

más cortos para atravesar las zonas desérticas o de alta montaña.

La conducción de ganado a pie la realizaban arrieros indígenas a modo de capataz u hombre de confianza, quien llevaba las tropas hasta los centros de venta o ferias de ganado; para esta tarea contaban con mano de obra especializada en la conducción (baqueanos), buenos conocedores de los caminos, sendas, pasturas y aguadas a las que se podía acceder en cada jornada, personal de amanse y toda la gama de peones y aprendices en el arreo (Sanhueza, 1992; Molina, 2011).

La particularidad de la arriería en la puna al sur del salar de Atacama es que se movilizaba animales y mercancías al mismo tiempo por caminos no directos por las serranías puneñas. Aquí el arriero indígena celebra tratos con un tercero (empresarios de la carne) para el traslado de animales de a pie, para ello contrataba personal especializado en las distintas faenas de esta actividad. Al mismo tiempo, de forma independiente compra artículos y productos como máquinas de coser, loza-vajilla, radios y también traslada sacos de hoja de coca, que intercambia por los alrededores de las rutas recorridas.

En este contexto los arrieros de Socaire durante gran parte del siglo XX trasladaron toros desde Salta (Argentina) hacia las costas de Chile, y desde los años 30, con la llegada de camiones y la construcción de nuevos caminos (Richard et al., 2018), disminuyó el viaje solo hasta el poblado de Socaire, donde embarcaban a los animales para su traslado en camiones hacia Calama y luego a Antofagasta. Nos cuenta la hija de un gran arriero socaireño;

“Mi papá, nació en $1915 \ldots$ a los 15 años se fue a Argentina, luego desde 1930 hasta que murió en 1960, siempre se dedicó al traslado de animales y mercadería, tarros de grasa 50 kilos, aceite 5 litros, con su socio Silvestre Varas, luego siguieron mis hermanos hasta más o menos 1987" (hija de arriero, Peine, 2017).

El viaje se iniciaba en las serranías de Salta, él traslada ganado vacuno macho, "toros", cercanos a 


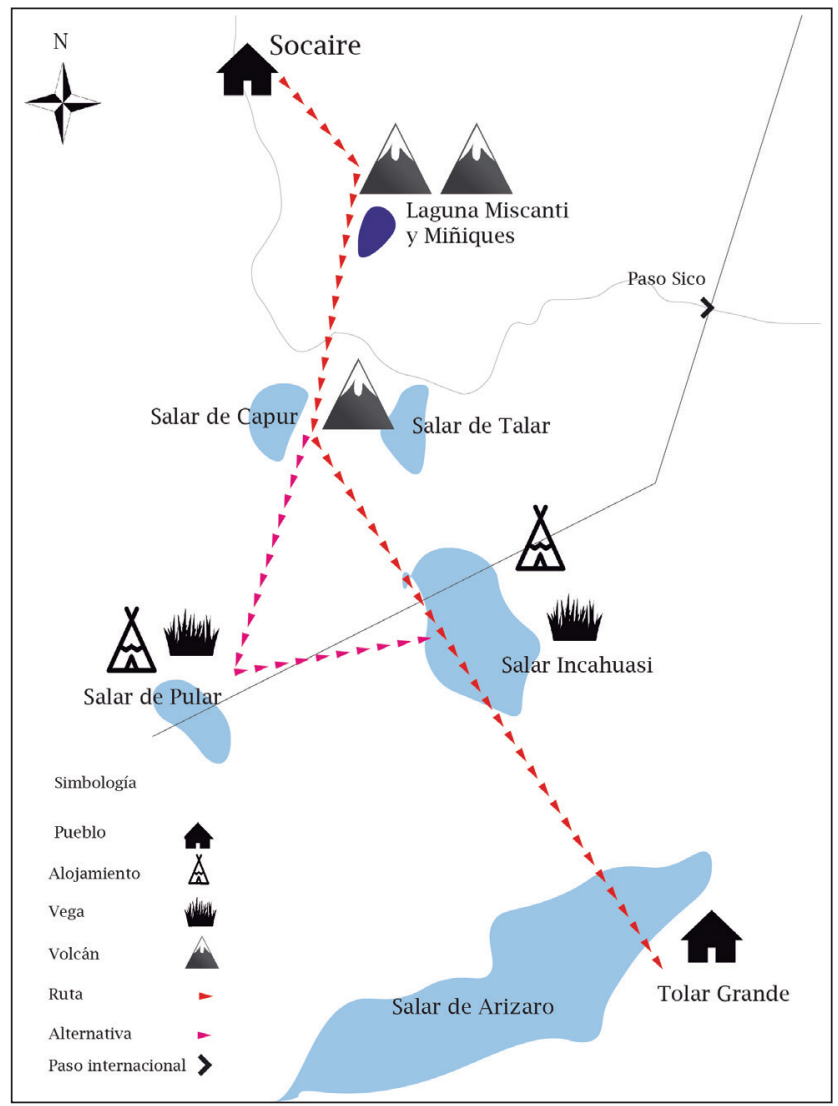

Figura 4. Espacialidad y conexiones Socaire-Antofagasta de la Sierra (sector norte).

Fuente: Elaboración Gisella Dibona.

los 100 o más, hasta el poblado de Socaire, donde estaban un par de días en los potreros alimentándose, hasta que eran trasladados en camiones con doble baranda a Calama y Antofagasta, donde se encontraban los frigoríficos de la empresa Abaroa. Asimismo, nos cuenta un exarriero de Socaire que el retorno a Salta desde Socaire se realizaba con 12 mulas cargadas con dos máquinas de coser por mula, una a cada lado, es decir, seis en total, y el resto era vajilla de loza. También se trasladaban sacos de hoja de coca. Más tarde, desde los años 50 en adelante se agregan radios y otros objetos electrónicos, siempre con sacos de coca.

Acerca de estas mercancías, la misma Nadia recuerda:

"En mi casa siempre había máquinas de coser, cerca de 10 almacenadas, también había vajillas de loza y sacos de hoja de coca, listas para ser trasladados a Argentina... los grandotes eran Silvestre

\section{Varas, Roberto Mora y Pedro Plaza" (hija} de arriero, Peine, 2017).

Ella distingue tres "grandotes" o vecinos acaudalados, uno de ellos era su padre y menciona que tenía amistad con un tal doctor Montt, el juez de Calama y el senador William Thayer, también del alcalde de Calama, del intendente y menciona que participaban de elecciones políticas.

También recuerda que su padre contrataba peones para faenas agrícolas, ganaderas y de arrieraje de animales. Normalmente estos eran vecinos o familiares no cercanos, y a quienes se pagaba con mercadería (con lana o ropa). También solía contratar algunas señoras en tareas domésticas como el lavado de ropa o el cuidado de animales.

Podemos entonces caracterizar una actividad que dispone de una estructura económica donde hay un arriero-comerciante jefe (Silvestre Varas, Roberto Mora y Pedro Plaza), y varias funciones subalternas que coordinaba contratando personas 


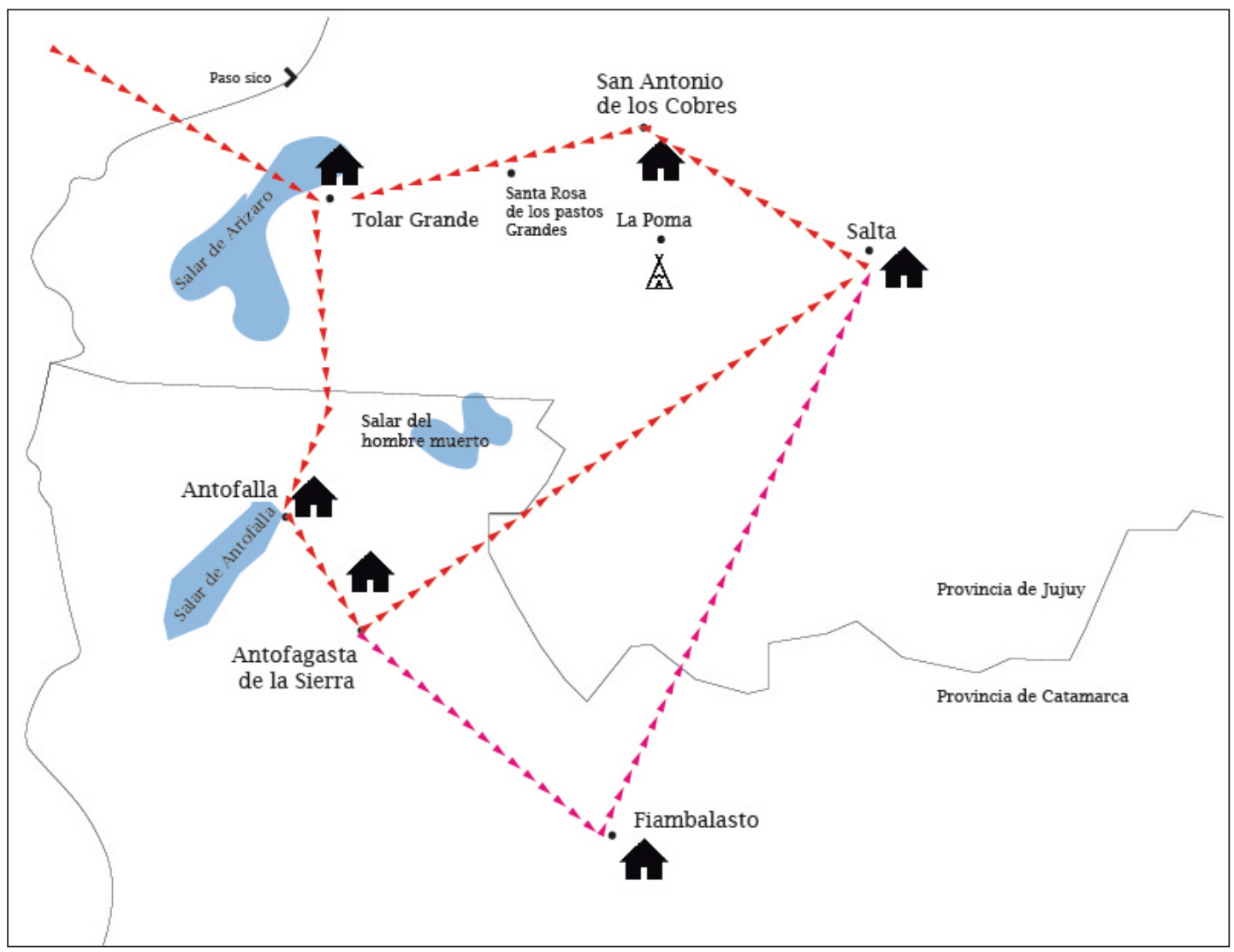

Figura 5. Espacialidad y conexiones Socaire-Antofagasta de la Sierra (sector sur).

Fuente: Elaboración Gisella Dibona.

por dinero y a otros pagándoles con productos alimenticios como aceite, azúcar, arroz y tarros de grasa, entre otros.

“Sí po', mejores casas, don Silvestre tenía hartas piezas ahí, ahí llegaban todos donde Silvestre, ahí llegaban, ¿Sabe quién llegó a la casa cuando en ese tiempo era ministro? William... pero llegaron cuatro ministros a alojar a su casa, eran de esos grandotes, venía gente de Santiago, de Antofagasta, llegaba el alcalde, el intendente, llegaban gente que él cuando hacían las propagandas llegaban con sus viejitos" (hija de arriero, Peine, 2017).

En este marco, un arriero-comerciante jefe disponía de medios de producción que fueron evolucionando con el tiempo, no en su cantidad, sino en su tipo y capacidad. Desde aproximadamente 12 mulas con que solían contar hasta la década del
60, luego se compraron dos camiones, al mismo tiempo que se contaba con corrales y almacenes en el poblado, en distintos lugares de las rutas que recorrían y redes (amistades) que le facilitaban la movilidad.

Nuestros informantes utilizan comúnmente la palabra "contrabando" para dar cuenta de una actividad ilegal. En nuestro caso se trata de una práctica que ocurría por la ausencia de controles fronterizos tanto argentinos como chilenos. Se trasladaba de Chile a Argentina sacos de coca, máquinas de coser, loza y radios; mientras que desde Argentina a Chile alimentos no perecibles, tarros de grasa de 40 kilos, aceites de cocina de 5 litros, y también llamos y caballos. La ilegalidad de la actividad se expresa de la siguiente manera en el relato:

"Un camión, compró un camioncito viejito, no era muy bueno, después se compró uno más nuevo, y justo él andaba haciendo ese matute para pagar ese camión, porque 
lo estaba debiendo y ahí lo pillaron, y él tenía unos llamos acá, yo, cuando a él lo tomaron preso yo vine, vendí los llamos y pagué como dos letras del camión" (hija de arriero, Peine, 2017).

Respecto de las amistades y contactos se hace referencia a un episodio de detención y encarcelamiento de su padre, mostrándonos el modo en que se creaban y utilizaban verdaderas redes de protección en las distintas esferas de la vida social calameña.

\begin{abstract}
"Era un juez, un juez, un viejito, era un juez entonces mi papá fue, y le cuenta ya, ya lo habían llevado detenido y todo, y va al juez, y terció justo con él, que lo llevaron al juzgado y era él y entonces va y dijo que le dice él -ya, yo lo voy a arreglar-después llega el doctor Montt, porque el juez le dijo que se hiciera el enfermo ahí en la cárcel, ya se lo habían llevado detenido, que estuviera muy enfermo, y ya po', fue el doctor, y el mismo juez lo llevó al doctor, el doctor lo examinó y le dijo -no, esto lo llevamos al hospital-y lo llevaron al hospital a mi papá, y estuvo ahí hasta que se arregló todo y ahí lo soltaron, estuvo como tres días, y eso, no estuvo ni tres días en la cárcel" (hija de arriero, Peine, 2017).
\end{abstract}

Respecto de otro encarcelamiento en Argentina también menciona que "mi hermano... lo pillaron y lo llevaron los gendarmes preso, estuvo cerca de un año en Catamarca, Argentina" (hija de arriero, Peine, 2017). La actividad de contrabando tenía sus riesgos y estos eran asumidos en más de una ocasión con cárcel, la narración anterior menciona la prisión por cerca de un año de un arriero en Catamarca y su posterior deportación a Chile. Si bien se trató de una actividad peligrosa y que requirió siempre de grandes esfuerzos, con jornadas de tres meses de traslado de mercancías diversas, ello permitió formas de acumulación de riqueza. Se pagaba con dinero las actividades propias del arrieraje, al peón ayudante, al peón tenedor y peón madrinero (cocinero, alimentar recua, dar agua a los animales). Respecto de los pagos con alimento, las siguientes actividades estaban bajo esta modalidad: trabajos de lavar y cuidar corderos (empleos domésticos), peón agrícola, forraje (temporal), esquila de animales (temporal), y se empleaba gente cuando llegan los animales y se debían conducir a los corrales, alimentarlos y subirlos a los camiones. La hija de uno de los jefes-arrieros comenta:

"don Alberto Mora, don Silvestre Varas, mi papá, eran los que, los grandotes... yo me acuerdo, una señora pobrecita, iba siempre a trabajar a la casa, le pedía trabajo a mi mamá, y ella le daba a veces trabajo para lavar, para ir a cuidar los corderos, cositas así y era muy pobre la señora, el marido era bien flojito, no trabajaba... Bueno, en ese tiempo no usábamos nadie zapatos, nosotros teníamos unos zapatos para las fiestas, claro, nos compraban, mi papá iba a Calama y nos traía zapatos, juguetes, unos juguetes de goma bien bonitos, me acuerdo, unos chanchitos, unas vaquitas, eran bonitos, pero él traía más mercadería, y él no compraba nunca por kilo, él traía sacos de arroz, sacos de azúcar, la fruta nos llevaba por cajones, un cajón de manzana y un cajón de naranja" (hija de arriero, Peine, 2017).

Este fragmento nos muestra diferencias sociales notables, personas que lideraban procesos productivos y otros que participaban como empleados y jornales. Estas diferencias se expresan en el acceso a bienes de consumo, pudiendo establecerse que existen verdaderas clases sociales con disponibilidad de recursos y con capacidad de acumulación, contratando fuerza de trabajo vía salario o pago en especies, y que disponían de medios de producción necesarios para realizar los negocios encomendados. Por otro lado, existía un grupo subalterno que vendía o intercambiaba fuerza de trabajo, vecinos pobres que eran contratados en distintas faenas productivas y domésticas. Esto nos muestra un grupo social heterogéneo. Las redes de comercialización regional se constituían por diversas personas, en las cadenas de traslado de animales y mercancías. Se encuentra en archivos locales y por relatos a un empresario de la industria del alimento quien pagaba el traslado de animales de pie (toros), desde 1916 "don Andrónico" (Andrónico Abaroa Rivas) y luego "don Juan” (Juan Abaroa Rodríguez) desde 1948, los últimos viajes fueron 1970-77 y se realizaron para abastecer los frigoríficos y terminal de desposte en Antofagasta. 
Tabla 3. Productos que se comercializaban.

\begin{tabular}{|c|c|c|c|}
\hline Productos & Tipo & Origen & Destino \\
\hline $\begin{array}{l}\text { Ollas, crema lechuga, almidón de mandioca, } \\
\text { máquina de coser, radios }\end{array}$ & Manufacturado/ Industrial & $\begin{array}{c}\text { Chile } \\
\text { San Pedro, Socaire, Calama }\end{array}$ & Argentina \\
\hline Toros de pie & $\begin{array}{l}\text { Ganadero } \\
\text { /derivados }\end{array}$ & $\begin{array}{l}\text { Argentina } \\
\text { Salta }\end{array}$ & $\begin{array}{c}\text { Chile } \\
\text { Antofagasta } \\
\text { Calama }\end{array}$ \\
\hline Mercadería, harina, frangolla & Industrial & $\begin{array}{c}\text { Argentina } \\
\text { Valles de Salta y Jujuy }\end{array}$ & $\begin{array}{c}\text { Chile } \\
\text { Toconao, Socaire, Talabre }\end{array}$ \\
\hline
\end{tabular}

Fuente: Elaboración propia.

\section{Conclusiones}

Las economías, rutas y espacios generados por los viajes relevan la importancia de la familia, los comerciantes y los caciques locales (grandotes), en las prácticas de traslado de diversas mercancías a distantes lugares en la puna. Podemos señalar que los viajes cuyo objetivo era el intercambio fueron con los años cristalizando distintos nodos y jerarquías dentro de la puna atacameña. Si bien se ha visto este espacio como unidad de intercambio relativamente estable entre los sujetos pastores y sujetos agrícolas, poco o casi nulo hincapié se ha realizado a la diferenciación social presente dentro de los grupos humanos que han habitado ese espacio. La comunidad homogénea y estable con la que se describe a los distintos grupos de la puna atacameña solo invisibiliza procesos de mayor complejidad como estructuras jerárquicas que emergen en los complicados viajes que se sostuvieron. La sociedad atacameña expresa su total diversidad en cada uno de los viajes descritos, siendo sus rasgos distintivos de cada uno de ellos, ser un trueque funcional, comercio de productos o traslado de mercancía, si bien se entremezclan, dan cuenta de una actividad diversificada que recoge toda la experiencia y experticia de los pastores trashumantes puneños. Los viajes familiares serán parte de una antiquísima tradición de intercambio y trueque de productos que producían las unidades campesinas indígenas familiares y que se inscribían de un modo de producción doméstica de autosubsistencia, se intercambiaba lo justo y necesario para mantener un modo de vida, asociando a la complementariedad productos de naturaleza ganadera, pastoril y agrícola, en las distintas quebradas de la puna. Los viajes comerciales en cambio tenían un propósito muy distinto, este era generar utilidades y ganancias con distintos productos ganaderos, pastoriles, agrícolas y manufacturados. Se establecían redes comerciales que hacían posible el traslado, almacenamiento y distribución de productos, que por su volumen generaban excedentes, apropiados por los comerciantes que hacían posible estos intercambios que requerían de coordinaciones y gestión de los circuitos. Por otro lado, el traslado de animales (toros a pie) es una actividad legal sometida a los controles aduaneros, asociada a tratos de traslado a modo de "flete" y ulterior contratación asalariada de empleados o peones. Sin embargo, esta misma actividad está asociada a contrabando de productos, soslayando controles de aduanas y policías. Los arrieros-jefes o los grandotes son la columna vertebral de una actividad tradicional asociada al trueque y al mismo tiempo actividades formales vía contrato de traslado o carga de animales, "todos" hacia la costa minera de Chile. El contrabando de radios, máquinas de coser, sacos de hoja de coca, de alimentos no perecibles, de llamas, de caballos dará a esta epopeya una condición épica, asociada a la ilegalidad propia de esta esfera de los viajes; trasladarse de noche, evitar los controles aduaneros y vigilancia policial, también asumir las prisión y el requisamiento de mercancía, serán el ir y venir de estos "grandotes" intrépidos baqueanos, comerciantes, contrabandistas que abastecen lugares remotos de productos básicos como el arroz, el azúcar o la hoja de coca.

Quizás un hecho llamativo de estos "grandotes" es su capacidad de instalar redes y asociaciones con empresarios y políticos, pero al mismo tiempo abastecer poblaciones con productos necesarios para mejorar el bienestar cotidiano. Con todo, la acción de los grandotes es un marcador de la diferenciación social y política al interior de estas comunidades. 
Estos grandotes además de ser líderes, empresarios o caciques políticos, también conocían de la naturaleza de la puna y las creencias religiosas atacameñas en torno a las quebradas, huellas, gentilares, también de antepasados, abuelos y malkus.

Finalmente estos viajeros, pastores, arrieros, comerciantes y "grandotes" serán personajes para cuentos de niños, benefactores, al mismo tiempo que bandidos, indígenas y empresarios conocedores del frío y el viento, de los rituales y gentilares. Serán los que trasladaron la modernidad de las máquinas de coser y radios a mediados del siglo XX a lugares remotos; los que abastecían de hojas de coca a los incansables trabajadores de la puna; los que llevaban el alcohol a las fiestas y ceremonias; los del trueque y la compra-venta.

\section{Referencias Citadas}

Alberti G. y Mayer E.

1977 "Las punas de los Andes Centrales" en Pastores de Puna. Uywamichiq punarumakuna .I.E.P. Perú-Lima.

Barros, A.

2008 "Identidades y propiedades: Transiciones territoriales en el siglo XIX atacameño". Estudios Atacameños 35: 119-139. Doi: 10.4067/S0718-10432008000100007

Benedetti, A. y Argañaraz, C.

2001 Simposio Fronteras y Corredores. La Puna de 1900 hasta el "Paso de Jama". Notas sobre el imaginario de los susqueños acerca del proceso de integración entre Chile y Argentina (págs. 1213-1228). Santiago de Chile: Colegio de Antropólogos de Chile A. G.

Benedetti, A.

2005 "La Puna de Atacama como construcción geopolítica (1879-1900). La redefinición del mapa político argentino tras la guerra del pacífico". Si Somos Americanos. Revista de Estudios Transfronterizos 7 (2): 155-183.

Berenguer, J. y Pimentel, G.

2017 "Introducción al estudio de los espacios internodales y su aporte a la historia, naturaleza y dinámica de las ocupaciones humanas en zonas áridas". Estudios Atacameños 56: 3-11.

Bowman, I.

1941[1924] "Los senderos del Desierto de Atacama". Traducido por Emilia Romero. Revista Chilena de Historia y Geografía 99:159-272.

Conti, V. y Sica G.

2011 "Arrieros andinos de la Colonia a la Independencia". Nuevo Mundo Mundos Nuevos No 11; DOI: 10.4000.

Garcés, A. y Maureira, M.

2018 "De familia a organización étnica: redes para una espacialidad transfronteriza en la Puna de Atacama". Revista Chilena de Antropología 37: 230-248. doi: 10.5354/0719-1472.2018.49514.

García, S.; Rolani, D.; López, M. y Valeri, P.

2002 "Viajes comerciales de intercambio en el departamento de Antofagasta de la Sierra, Puna Meridional argentina: pasado y presente". Revista Hispana para el Análisis de Redes Sociales 2 (5):1-24.

Gil Montero, R.

2004 "Población, medio ambiente y economía en la Puna de Jujuy, Argentina, siglo XIX". Revista de Demografía Histórica ISSN 1696-702X, Vol. 22, N 1: 185-208.

Gundermann H. y Vergara, J.

2009 "Comunidad, organización y complejidad social andinas en el norte de Chile". Estudios Atacameños 38:107-126.
Haber, A. y Lema, C.

2006 "Dime cómo escribes y te diré quien eres. Textualizaciones del campesinado indígena de la Puna de Atacama". Memoria Americana14: 119-137.

Haber, A.; Lema, C. y Quesada M.

2006 "Silenciamiento de la persistencia indígena en la Puna de Atacama". Aportes Científicos desde Humanidades 6 : 190-198.

Haber, A.; Lema, C. y Granizo, G.

2007 La Construcción del Paisaje Aldeano en la Puna de Atacama. Siglos XII a XVII. Congreso Chileno de Antropología. Colegio de Antropólogos de Chile A. G, Valdivia.

Hidalgo, J.

2004 "Cambios culturales de Atacama en el siglo XVIII: Lengua, escuela, fugas y complementariedad ecológica". En J. Hidalgo, Historia andina en Chile. Santiago. Editorial Universitaria.

Hidalgo, J. y Manríquez, V.

2004 "Mercado y etnicidad de la Revisita de Atacama de 1683". En J. Hidalgo, Historia andina en Chile. Santiago. Editorial Universitaria.

Latcham, R.

1938 Arqueología de la Región Atacameña. Universidad de Chile. Santiago, Chile.

Londoño, W.

2018 "La puna de atacama y el problema de la otredad: una mirada a la primera mitad del siglo XX". Estudios Atacameños 55: 219-230.

Murra, J.

1975 Formación económica y política del mundo andino. Lima I.E.P.

Molina, R.

2011 "Los otros arrieros de los valles, la puna y el desierto de Atacama". Chungara, Revista de Antropología Chilena 43(2): $177-187$

Mostny, G.

1954 Peine un Pueblo Atacameño. Editorial Universitaria. Santiago, Chile.

Morales, H.; González, L.; Dibona, G.; Vilches, J. y Azócar, R. 2018 "Viajes e intercambios entre las comunidades argentinas y chilenas en la puna atacameña (segunda mitad del siglo XX)". Revista Chilena de Antropología 37: 249-266. doi:10.5354/0719-1472.2018.49515.

Núñez, M.

2002 Transformaciones culturales en Toconao por impacto de empresas mineras: un estudio de caso en el norte de 
Chile. Tesis de magíster en Antropología. Universidad de Chile, Santiago de Chile.

Richard, N.; Moraga, J. y Saavedra, A.

2016 "El camión en la puna de atacama (1930-1980): mecánica, espacio y saberes en torno a un objeto técnico liminal". Estudios Atacameños 52: 177-199.

\section{Sanhueza, C.}

2001 "Las poblaciones de la puna de Atacama y su relación con los estados nacionales. Una lectura desde el archivo". Revista de Historia Indígena 5: 55-82.

Sanhueza, C.

1992 "Tráfico caravanero y arriería colonial en el siglo XVI", en Revista Estudios Atacameños 10: 173-187.

\section{Notas}

$1 \quad$ Algo similar describe Raquel Gil Montero (2004) para el sur de Lípez en pleno siglo XVII.

2 Eloy Luzco atravesó durante los últimos 50 años estos parajes puneños durante días, semanas y meses con sus burros, mulas y llamas, recorriendo inmensos salares y estepas de alturas rumbo a quebradas y valles donde trueca alimentos y frutas a cambio de tejidos o sal. Un Documental de Blas Moreau muestra la vida de un pastor de llamas y ovejas, tejedor, y arriero de la puna jujeña en el documental "Eloy Luzco, retrato de un arriero". 
